\title{
The Precision and Accuracy of English Verbs Choice in Recount Text Written by the Students of CEC Denpasar: An Analysis of Metalanguage
}

\author{
Ni Nyoman Dewi Astari Putri ${ }^{1}$, I Wayan Pastika ${ }^{2}$, Made Sri Satyawati ${ }^{3}$ \\ Faculty of Arts, Udayana University 1,2,3 \\ e-mail: dewiastariputri23@gmail.com ${ }^{1}$, wayanpastika@unud.ac.id ${ }^{2}, \underline{\text { srisatyawati@unud.ac.id }}^{3}$
}

\begin{abstract}
This writing entitled "The Precision and Accuracy of English Verbs Choice in Recount Text Written by The Students of CEC Denpasar: An Analysis of Metalanguage" was conducted in order to be able to find out the percentage of precision and accuracy of English verbs choice in recount text written by the students of CEC Denpasar, analyze the lexico-semantic error, and describe the factors that cause this error. The data in this study were taken directly from recount texts written by the students of CEC Denpasar, interview, and questionnaire. Those data were collected by using a test, interview, and questionnaire method. The theory applied in this writing is Metalanguage from NSM theory proposed by Wierzbicka (1996). However, in describing the error, the analysis was done through configuration only by the qualitative method. The result shows that out of twentysix verbs, twelve chosen verbs were less precise. Through Metalanguage, those errors can be described configurationally. Moreover, the difference between the error and the recommendation verbs can be explained, therefore, the difference can be shown. There were two factors that cause this error. They are external (teacher, method, strategy, technique used in teaching) and internal (motivation, potency, competence, and learners' language background) factors.
\end{abstract}

Keywords: verb choice, lexical verb, metalanguage, recount text, lexico-semantic

\section{INTRODUCTION}

Every language has a word class which refers to the verb, no matter what language it is (Chafe, 1970). Dixon (1991:9) also argues that the verb is the core of a clause and sentence as it presupposes a number of participants, i.e. one, two or three depending on the semantic concern. In Merriam Webster Dictionary, it is explained that verb is "a word that is the grammatical center of a predicate and expresses an act, occurrence, or mode of being, that in various languages is inflected for agreement with the subject, for tense, for voice, for mood, or for aspect".

From the definition above, it is known that the verb plays an important role in composing a clause or sentence. Choosing a verb to express certain meanings is unique. It is because of some verbs such as see, look, watch, glare, stare, gaze, and peek have the same field of meaning that is 'melihat'. Although they share the same field of meaning, the meaning of those verbs is not exactly the same at all. This is one of the general semantic rules that stated 
different forms of a lexicon will have a different meaning (Chaer, 1990:39). It means if two or more words have a different form, it means the meaning of those words is not the same at all.

The fact that the English verb has some lexicon that belongs to the same field of meaning leads to a problem for the students of CEC Denpasar. As ESL learners, their knowledge and understanding about the different usage of those verbs are still lacked. As a result, errors in choosing a verb can be found both in written and oral communication.

Precision and accuracy in choosing English verbs are very important for the students of CEC Denpasar to avoid misunderstanding since what they want to say is not expressed well by the sentence they utter. In addition, some researches have written by Sheorey (1986), Chastain (1981), and Politzer (1978) show that vocabulary error (one of them is a verb) is the most serious barrier to the comprehension of understanding utterances. It is because choosing improper verb can affect the effectiveness of communication as it doesn't express exactly what the speaker wants to say. Here is one example:

"I need my laptop. Could you please take it to me? It is on my chair."

Verb 'take' in this sentence implies that the laptop will be taken away from the speaker. Nevertheless, the speaker wants the listener to bring the laptop toward her. Therefore, this verb should be 'bring' as this verb implies movement toward the speaker. Although these verbs have the same field of meaning 'membawa', they have subtle differences and imply a different way of movement. Hence, choosing a less precise verb to express something will affect the effectiveness of communication and lead to misunderstanding.

This type of error is known as lexico-semantic error. Based on its classification, the lexico-semantic error is linguistic-based classification. The lexico-semantic error means the incorrect word is used to express a certain meaning (Keshavarz, 2012;57). Lexico-semantic emphasizes the meaning of a word as an independent unit. The lexical meaning can be known by looking at a dictionary. However, the dictionary cannot always help. Some words refer to one another. Here is the example is taken from https://www.oxfordlearnersdict ionaries.com/:

Ask à to request permission to do something

Request à the action of asking for something formally and politely

The definition of ' $a \mathrm{sk}^{\prime}$ and 'request' refer to one another; therefore, the student will be confused to choose the best verb as they do not understand the difference between these verbs. This problem leads to a lexico-semantic error. In semantic, there is a study namely Natural 
Semantic Metalanguage (NSM). NSM is a theory proposed by Anna Wierzbicka. The basic assumption of this theory is "semantic analysis must be conducted in natural language, because technical neologisms, logical formalisms, etc., are not clear until and unless they are explained in ordinary language". In addition "any complex meaning can be decomposed without circularity and without residue into a combination of discrete other meanings". NSM is done in two stages. The first stage is configuration, while the second is explication. Through these stages, the subtle difference of a lexicon (one of them is a verb) can be found out. The subtle difference can be used to explain the difference among lexicons that have the same field of meaning. The subtle difference consists of an entity, instrument, method, psychological state, and the result.

From the phenomenon and examples given in the previous paragraphs, it is very important to analyze the precision and accuracy of English verb choice because this problem is urgent to be discussed. There are three aims of this study. They are to find out the percentage of precision and accuracy of English verb choice in recount text written by the students of CEC Denpasar, analyze the lexico-semantic error, and describe the factors that cause this error.

In order to be able to give a deeper analysis, it is very important to state the limitation in this study. This study emphasizes lexico-semantic error especially in the precision and accuracy of English verb choice. The category of the verb is the lexical verb found in recount text written by the student of CEC Denpasar. The lexical verb has a very broad possibility of meaning, therefore, the meaning of the lexical verb is analyzed configurationally through Metalanguage and is limited to denotation meaning because this meaning is easier to be postulated. Configuration helps to find out the subtle difference between the chosen verb and its alternative as well to describe the usage; therefore, the difference can be shown.

\section{METHOD}

The data in this study were taken by using a test, interview, and questionnaire. In analyzing the data, descriptive quantitative and qualitative were used in this study. The quantitative data were taken from the number of accurate verbs chosen by the students, while qualitative data were taken from interviews and questionnaires. There were some steps in analyzing the data. First, all of the lexical verbs in the recount text were grouped into two categories. The first group consists of a precise verb, while the second is a less precise verb. The purpose is to count the percentage of accurate verb chosen by the students. Next, the lexical verb that indicates a lexico-semantic error was analyzed through Metalanguage. The analysis was done configurationally to find out the subtle difference; therefore, it can be 
shown the difference between the chosen verb and alternative verb. The last, interview and questionnaire were analyzed to find out the factors causing the lexico-semantic error.

\section{RESULT AND DISCUSSION}

After analyzing the data, there are three points presented in this part. The first point is the percentage of precision and accuracy of English verb choice in recount text written by the students of CEC Denpasar. The second point is the analysis of the lexico-semantic error through Metalanguage. The last point is the factors that cause this error. The result and discussion of those points can be presented below.

\subsection{The Percentage of Precision and} Accuracy of English Verbs Choice in Recount Text Written by The Students of CEC Denpasar

Out of twenty-six verbs found in the recount texts, twelve chosen verbs $(46,15 \%)$ were less precise as they didn't present the meaning that the speakers wanted to express. However, fourteen verbs $(53,84 \%)$ were already chosen precisely. Although the amount of precisely chosen verbs is higher than the less precise verbs, the difference is only 7 , $69 \%$. It showed that choosing a verb is one of the problems for the students of CEC Denpasar.
3.2 Lexico-Semantic Error of Verb Choice in Recount Text Written by The Students of CEC Denpasar

There was twelve chosen verb that was less precise. From those verbs, they belonged to five verbs. Those verbs were hear, talk, look, shout, and see. The analysis of those verbs can be presented as below.

Last weekend,

I heard songs before I took a bath

The verb 'heard' mean 'mendengar' in Bahasa Indonesia. The basic lexical form of this verb is 'hear'. This lexicon was chosen less precisely because the activity 'hear' in the data (2-1) has a different meaning compared to what the speakers want to say. The lexicon should be listen. In Oxford Advanced Learner's Dictionary, it is explained that verb 'hear' means "to be aware of sounds with your ears" while listen means "to pay attention to somebody or something that you can hear". Although these verbs have similarities, these verbs have a subtle difference. The subtle difference can be explained by Metalanguage.

From the Metalanguage point of view, both activities 'hear' and 'listen' need agent and object as the entity. The agents of these activities are animate, while the objects can be animate or inanimate. The actors do these activities using their sense of hearing. However, the purpose of doing 'hear' and 'listen' is different. When the actor does activity 'listen', there is the effort needed by the actor to listen to it carefully. It is because the verb 'listen' implies that 
the actor tries to understand the content of conversation he is listening to, find the source of the sound, and gain information. In contrast, the verb 'hear' is done by the agent because he has a sense of hearing. In other words, the agent does it naturally without any effort. In addition, the psychological state of activity 'listen' shows curiosity from the agent, while the activity 'hear' describe that the agent doesn't have any intention to do it as it is done naturally. Therefore, the verb 'hear' in the data above should be replaced by 'listen' as this verb describes what the speaker wants to express.

(2-2) I looked at her angrily.

The verb 'looked' is the second form of 'look'. This verb means 'melihat'. 'Look' means "to turn your eyes in a particular direction" (Hornby, 2012). In other words, this activity expresses an action done by the agent by turning his eyes to a particular direction. From the context in the data above, the verb 'look' was less precise because there is no anger expressed in this verb. Therefore, this verb should be replaced by 'glare'. 'Glare' means "to look at somebody or something in an angry way" (Hornby, 2012). This verb can describe the psychological state of the agent who is in anger by looking at the person who causes his anger.

In addition, these two verbs have other subtle differences. It is the result of doing an activity 'look' and 'glare'. The agent does activity 'glare' because he wants the object to knows that he is angry. In contrast, the activity 'look' expresses that the agent wants to see the object to find out information or because of curiosity.

Although these verbs have some differences, they have similar components of configuration such as entity and instrument. Both of these activities are done by animate as the agent toward animate or inanimate as the object. In addition, the instrument is the same that is the sense of sight.

(2-3) She turned off my laptop and talked to me about her boyfriend.

The base form of 'talked' is 'talk'. According to Merriam Webster dictionary, 'talk' can be described as "to express or exchange ideas by means of spoken words and to convey information or communicate in any way (as with signs or sounds)". From the given context in the data (2-3), it is known that the verb 'talk' is chosen less precisely. 'Talk' implies that the hearer participates in the conversation by sharing ideas or opinions and giving comments. However, the hearer in the data above just listens to the speaker. Therefore, the verb 'talk' should be replaced by 'tell'. In Oxford Advanced Learner's Dictionary, it is stated that 'tell' means "to give information to somebody by speaking or writing".

Configurationally, the verb 'talk' and 'tell' have the same entity. These activities are done by animate as the agent toward animate as the object. However, the media used in these activities are not the same. In doing activity 'talk', the agent uses utterance or oral communication, 
while 'tell' can use written or oral communication. Moreover, the involvement of the hearer when the speakers do this activity is also different. When the agent does activity 'talk', the hearer is also involved in the conversation, while inactivity 'tell', the hearer doesn't take part in conversation because the hearer listens and pays attention to what the speaker says. From the explanation, it can be concluded that 'tell' is better to be used in the data (23 ) as the hearer in this data focus on listening only.

(2-4) She shout to me when she realized that I didn't hear her

'Shout' means 'berteriak' in Bahasa Indonesia.

In Cambridge English Dictionary, it is known that 'shout' is "to speak with a very loud voice, often as loud as possible, usually when you want to make yourself heard in noisy situations, or when the person you are talking to is a long way away or cannot hear very well". From the Metalanguage point of view, this verb is less precisely chosen because it does not represent the meaning and psychological state expressed in the data (2-4). Verb 'shout' should be replaced by 'yell'.

Both 'shout' and 'yell' have the same field of meaning; however, there are some differences between these verbs. 'Yell' can be described as "to shout or make a loud noise, usually when you are angry, in pain, or excited". Compare to the definition of 'shout', it can be known that the way the agents do these activities and the results are different. When the agent does activity 'shout', he, who is also the speaker, speaks louder in order to be able to be heard by the listener as the situation is crowded. In contrast, activity 'yell' shows that the agent speaks louder to express his feeling such as anger, happiness, and sadness. As a result, the psychological state implies in these verbs are different. 'Shout' is done without any emotion, while 'yell' is done with full of emotion. Therefore, 'yell' should be used in the data (2-4). In addition, the result of doing these activities are different. In verb 'shout', the agent (speaker) wants to attract the attention of the object (hearer) while in verb 'yell', the agent (speaker) wants to express his feelings.

(2-5) In the darkness, she saw the curtain in my room for a long time.

In this data, the base form of the verb 'saw' is 'see' which in Indonesian means 'melihat'. According to Hornby (2012), the verb 'see' can be described as "to be conscious of what is around you by using your eyes". This verb should not be used in data (2-5) because the agent looks at the curtain for a long time. When activity 'see' is done, the agent sees what is around him naturally without any intention.

This verb should be replaced by 'stare'. 'Stare' means "to look for a long time with the eyes wide open, especially when surprised, frightened, or thinking". Verb 'stare' represents the meaning that the agent wants to convey. In 
addition, it illustrates how the agent performs activity 'to see' which is expressed in the data (2-5).

Configurationally, the subtle difference of verb 'see' and 'stare' lie in the way as well as the psychological state. In activity 'see', the agents does it naturally because he has the sense of sight, while in the activity 'stare', the agents look at something for a long time because he feels scared when he realizes something is behind the curtain (object). Psychologically, activity 'stare' has emotional nuances such as fear, surprise or thinking while there is no emotional scene in the verb 'see'.

\subsection{Factors Causing Error in Lexico- Semantic (Verb)}

In general, choosing a less precise verb to express certain meanings is caused by two factors, namely internal and external factors. Internal factors come from the students themselves (language learners). These factors include motivation, potential, competence, and language background of learners. In contrast, external factors consist of teachers, methods, strategies and teaching techniques.

The first internal factor is motivation. Motivation plays an important role in the learning process. Without motivation, a person cannot do something to the maximum. This is because motivation is a kind of encouragement that originates from oneself that encourages someone to do something so that it can achieve something (goals) (Harmer, 2007; 98).
Furthermore, Brown (2007: 169) adds that ego is the main motivation because of the 'need for the self to be known and to be approved of by others' (one's need to be known and accepted by others).

Motivation comes from inside (intrinsic) or outside (extrinsic) of the learners. From the result of the interview and questionnaire, the students of CEC Denpasar have quite high motivation in learning English, especially extrinsic motivation related to learning goals. High motivation certainly affects the learning output.

The second internal factor is competence. Competence relates to the ability to master grammar in a language. Lacking competence associated with vocabulary and understanding toward the different usage of verbs that have the same field of meaning is the cause of errors in choosing a verb.

The third factor is the students' potential. Every learner has different potential. One can learn languages quickly, while others learn slower. This potential is known as language aptitude which consists of four components, namely phonetic coding, grammatical sensitivity, rote memorization, and inductive language learning (the ability to learn language inductively). Error in choosing verb (lexico-semantic error) found in recount text is related to rote memorization and inductive language learning.

The fourth internal factor is the background of the language. The students' mother tongue is Bahasa 
Indonesia which originates from the Austronesian language family, while English as a foreign language belongs to the Germanic language family. These two language families have significant differences resulting in language interference, as well as language transfer both phonological, morphological, grammatical, lexicosemantic and language style transfers due to the structure and characteristics of the students' mother tongue.

In addition to the internal factors above, there are several external factors that also affect the accuracy of verb choices. The first factor is the teacher. The teacher plays an important role in helping students to study. If the teacher does not master the topic being discussed, does not understand English well, and does not master linguistics, the teacher will have difficulty in delivering the material, especially regarding to the meaning of the verb, how to choose the precise verb, distinguish the meanings of several verbs that have the same field of meaning. This is because many language phenomena and language errors can be explained and helped by applying linguistics, for example, Metalanguage in providing information on different meanings and the use of lexicon with similar meanings.

Other external factors are the methods, strategies, and techniques applied by the teacher in teaching. The application of inappropriate methods, strategies, and techniques in learning verbs will give a bad result.
The bad result is students do not understand that verbs with the same field of meaning have a subtle difference that distinguishes the usage of those verbs. Therefore, in learning verb, metalanguage should be given to the students in order to be able to distinguish the meaning of one verb from another so they can choose the verb precisely.

\section{CONCLUSION}

From the explanation above, it can be concluded that the number of verbs found in the recount text is 26 verbs. Twelve verbs $(46,15 \%)$ were chosen less precisely as those verbs do not represent the meaning that the agent wants to convey. After analyzing using metalanguage, it is known that the verbs listen should be used instead of heard/hear, told instead of talked, staring instead of saw, yell instead of shout, and glared instead of look.

In general, there are two factors that cause students to choose verbs that are not appropriate to represent the intent they want to convey. These two factors are internal and external factors. Internal factors consist of motivation, potential, competence, and language background of learners, while external factors include teachers, methods, strategies and teaching techniques. 


\section{REFERENCES}

Brown, H. D. 2007. Principle of Language Learning and Teaching. Fifth edition. New York: Longman

Chafe, Wallace L. 1970. Meaning and the Structure of Language. Chicago: the University of Chicago Press.

Chastain, K. 1981. Native speaker evaluation of student composition errors. Modern Language Journal. Vol. 65, No. 2, pp.288-294

Dixon, R.M.W. 1991. A New Approach to English, on Semantic Principles. New York: Oxford University Pres.

Harmer, Jeremy. 2007. The practice of English

language teaching. Fourth edition. UK: Longman.

Hornby, A.S. 2012. Oxford advance learner's dictionary. Oxford: Oxford University Press.

Keshavarz, Mohammad Hossein. 2012. Contrastive Analysis $\mathcal{E}$
Error Analysis. Tehran:

Rahnama Press

Politzer, R. 1978. Errors of English speakers of Gennan as perceived and evaluated by German natives. Modern Language Journal, Vol. 62, pp. 253261Kbbi

Sheorey, R. 1986. Error perception of native-speaking and nonnative speaking teachers of ESL. ELT Journal, Vol. 40, No.4. pp.306-312.

Shout. 2020. In Cambridge English Dictionary. Diakses 2 Januari 2020, dari https://dictionary.cambridge.o rg/dictionary/english/shout

Talk. 2020. In Merriam-Webster.com. Diakses 2 Januari 2020 dari https://dictionary.cambridge.o $\mathrm{rg}$ /dictionary/english/talk.

Wierzbicka, A. 1996. Semantics: Primes and Universals. Oxford: Oxford University Press 